NBER WORKING PAPER SERIES

\title{
THE LONG AND THE SHORT OF IT: SOVEREIGN DEBT CRISES AND DEBT MATURITY
}

\author{
Raquel Fernández \\ Alberto Martin \\ Working Paper 20786 \\ http://www.nber.org/papers/w20786
NATIONAL BUREAU OF ECONOMIC RESEARCH
1050 Massachusetts Avenue
Cambridge, MA 02138
December 2014

We thank seminar participants at the Barcelona GSE Summer Forum, EIEF, IMF, LACEA, NBER IFM, NBER Macroeconomics Within and Across Borders, NYU, Princeton, Sveriges Riksbank, University of Oslo Debt Conference, University of Zurich Conference on Sovereign Debt, and the Workshop on the European Debt Crisis at the University of Rochester. We also thank Manuel Amador, Cristina Arellano, Olivier Blanchard, Marcus Brunnermeier, Marcos Chamon, Giovanni Dell'Ariccia, Olivier Jeanne, Luc Laeven, and Damiano Sandri for very helpful comments and discussions. Fernández acknowledges sup- port from the CV Starr Center and Martin acknowledges support from the Spanish Ministry of Science and Innovation (grant ECO2011-23197), the Generalitat de Catalunya-AGAUR (grant 2014SGR-830), the Barcelona GSE Research Network, the ERC (Consolidator Grant FP7-615651), and the IMF Research Fellowship. Part of this work was undertaken while both authors were visiting the IMF Research Department and we are grateful to its hospitality. The views expressed herein are those of the authors and do not necessarily reflect the views of the National Bureau of Economic Research.

NBER working papers are circulated for discussion and comment purposes. They have not been peerreviewed or been subject to the review by the NBER Board of Directors that accompanies official NBER publications.

(C) 2014 by Raquel Fernández and Alberto Martin. All rights reserved. Short sections of text, not to exceed two paragraphs, may be quoted without explicit permission provided that full credit, including (C) notice, is given to the source. 
The Long and the Short of It: Sovereign Debt Crises and Debt Maturity

Raquel Fernández and Alberto Martin

NBER Working Paper No. 20786

December 2014, Revised September 2015

JEL No. F33,F34,F36

\begin{abstract}
$\underline{\text { ABSTRACT }}$
We present a simple model of sovereign debt crises in which a country chooses its optimal mix of short and long-term bonds subject to standard contracting frictions: the country cannot commit to repay its debts nor to a specific path of future debt issues, and contracts cannot be made state contingent nor renegotiated. We show that, in order to reduce incentives to engage in debt dilution, the country must issue short-term debt. This exposes it to roll-over crises and inefficient repayments. We examine the effects of alternative restructuring regimes, which either write-down debt or extend its maturity in the event of crises, and show that both necessarily improve ex ante welfare if they do not decrease expected payments to creditors during crises. In particular, we show that the way in which these regimes redistribute payments between short- and long-term creditors, which has been a central point in recent policy debates, is inconsequential.
\end{abstract}

Raquel Fernández

Department of Economics

New York University

19 West 4th Street, 6th Floor

New York, NY 10012

and NBER

raquel.fernandez@nyu.edu

\author{
Alberto Martin \\ CREI \\ Universitat Pompeu Fabra \\ Ramon Trias Fargas, 25-27 \\ 08005 Barcelona \\ Spain \\ and Barcelona GSE \\ amartin@crei.cat
}




\section{Introduction}

Sovereign debt is once again at the center stage of the academic and policy debate. This attention has been largely fueled by the growth of public debt within the Eurozone, which has raised concerns regarding the ability of the current debt-restructuring framework to deal efficiently with large-scale debt crises. These concerns were vindicated by the experience of Greece, where the debt restructuring of 2012 is widely perceived to have come inefficiently late, after years of low growth and increasing official indebtedness.

It is against this backdrop that various reforms of the international lending framework are being discussed. ${ }^{1}$ Broadly speaking, the goal of these proposals is to make it easier for countries to deal effectively with large stocks of outstanding debt by facilitating restructurings. These proposals have generated a lively debate. Adherents stress their ex post benefits, i.e., they will help countries deal more efficiently with debt crises. Opponents emphasize instead their ex ante costs, i.e., by making restructuring easier, they will raise the cost of borrowing. A feature of several proposals is the option of a lighter restructuring - "reprofiling" - in the form of a lengthening of the maturity of debt that is coming due. ${ }^{2}$ This has raised the concern that short-term creditors will be negatively impacted, as they are more likely to be affected by the lengthening of maturity. ${ }^{3}$ As short-term debt is thought, for a variety of reasons, to play a critical role in the financing of sovereign debt, any change in its price may have significant repercussions.

Clearly, any reform of the restructuring process affects both the distribution of payoffs both between countries and their creditors and also among creditors themselves. Assessing their merits requires an analytical framework to address the following questions: What are their costs and benefits? What are their effects on short and long-term interest rates? How do they affect the likelihood and cost of debt crises? How will they impact a country's choice of maturity structure? The sovereign debt literature provides few models that allow an analysis of policy reforms in a simple and transparent fashion. The objective of this paper is to provide a simple framework that can be used to address these questions.

We develop a model that incorporates several features that are key to the study of sovereign borrowing. First, borrowing is subject to standard contracting frictions: debt contracts are non-contingent, they cannot be renegotiated ex post, and the country is unable to commit to a path of future debt issues or repayment. Second, the timing of payments can matter. When there is uncertainty regarding future outcomes, the refusal by existing creditors to roll-over their debt can result in the country taking measures that impact negatively on its overall ability to repay and to generate future output. Lastly, the country's debt maturity structure is endogenous.

The model features a small-open economy that borrows resources from the international financial market

\footnotetext{
${ }^{1}$ See Brooks and Lombardi (2015) for a recent review of these reform proposals.

${ }^{2}$ One such reform has been prominently advocated by the International Monetary Fund (see IMF 2014b). The call for the automatic reprofiling of debt also features in a proposal by the Bank of Canada and Bank of England (see Brooke et al (2013)).

${ }^{3}$ For an expostision of these arguments, see "Creditors likely losers from IMF Rethink" (Financial Times, 6/4/2013), "IMF sovereign debt plans in jeopardy" (Financial Times, 1/26/2014), and "Finance: In search of a better bailout" (Financial Times, $1 / 26 / 2014)$.
} 
in order to finance an ex-ante profitable investment opportunity. The project takes time to fully mature: early payments divert funding from the project (or from complementary infrastructure) and decrease its associated expected output. The country is subject to shocks, which affect its productivity and thus its ability and willingness to repay its debt. In this environment, short-term debt is costly because creditors may be unwilling to roll it over in the face of bad economic prospects, triggering a debt crisis. If the country could commit to a path of future debt issues, these risks could be avoided by issuing long-term debt. Absent this ability to commit though, long-term debt is also problematic. The reason is that, once issued, the country will be tempted to dilute it by issuing more debt in the future. In this regard, as in much of the recent sovereign debt literature that incorporates debt maturity, short-term debt plays a "disciplinary" role by reducing the incentive to dilute. This gives rise to a set of incentive compatible maturity structures that keep dilution in check. Key to choosing among these possible maturity structures is how they affect both the likelihood and the cost of debt crises. In equilibrium, the country's choice of maturity structure optimally trades off the costs and benefits of short-term debt.

We use the model to analyze the effects of alternative debt restructuring regimes. In particular, we assume that the country can request help from an international financial institution (e.g., the IMF) and that the latter chooses whether to intervene, i.e., restructuring is an equilibrium outcome. In the event of intervention, the IFI halts all payments to creditors as well as new borrowing by the country, and restructures outstanding debt following the guidelines of the regime, e.g. this regime could write down all debt proportionally or only that of a subset of creditors or it could lengthen the maturity of debt due that period. ${ }^{4}$

Any restructuring regime has both ex post and ex ante effects. Restructuring can enhance ex post efficiency by preventing inefficient payments during times of crises, which decrease the total net present value of resources to be shared between the country and its creditors. But restructuring regimes also affect the ex post distribution of resources between creditors and the country and among creditors themselves. Both ex post redistribution and efficiency enhancement will have ex ante effects on the relative cost of debt, on the optimal maturity structure, and on welfare.

Our main welfare result is as follows: a sufficient condition for a restructuring regime to increase ex ante welfare is that it not decrease the expected total value of payments to creditors during times of crises. This result is intuitive yet surprising. It implies that, despite the central role played by short-term debt, the way in which a regime distributes payments between short-term and long-term creditors during crises is irrelevant. What matters instead are total payments to creditors as a whole in these critical periods. This suggests that the debate over the merits of restructuring regimes should not be centered on the distribution of payments among creditors, but rather on the distribution of surplus between creditors and the debtor country. In addition, we show that restructuring regimes may need to offer ex post incentives in order for a country to be willing to restructure, potentially creating tension between ex ante and ex post efficiency.

\footnotetext{
${ }^{4}$ Given the large literature that already exists on the topic of solvency crises.(e.g., Calvo 1988, Cole and Kehoe 2000, Corsetti et al. 2006), we ignore self-fulfilling crises and the role for an IFI as a potential lender of last resort.
} 
Our paper complements the literature on the optimal maturity structure of debt. Most theories build on the notion that, in a context of incomplete markets, debts of different maturities allow for greater hedging of risk. ${ }^{5} \quad$ More relevant for our purposes, the maturity structure of debt may also impact the repayment prospects and incentives faced by a borrower who is unable to commit to a future path of actions. In a model of corporate debt with several features in common with ours, Brunnermeier and Ohemke (2013) show how a debtor's inability to commit to a debt maturity structure leads to a suboptimally short maturity structure. In the banking literature, Diamond and Rajan (2001) have shown how short-term debt may discipline borrowers and induce them to undertake certain actions that are desirable ex ante but which would not otherwise be incentive compatible ex post. ${ }^{6}$

This "disciplinary" view of short-term debt has been recently extended to the context of sovereign debt, where the critical additional assumption is the inability of a government to commit to repay its debts. ${ }^{7}$ In this context, as shown by Jeanne (2009), short-term debt can provide incentives even when the government can commit to a future path of debt issues and hence is immune to the temptation to dilute. Instead, the role of short-term debt is to expose the government to costly roll-over crises in the absence of pro-market reforms, rendering the latter incentive compatible. ${ }^{8}$ More recently, Aguiar and Amador (2014) show that short-term debt provides governments with greater incentive to deleverage than the equivalent long-term debt. This stems from the need to roll over short-term debt every period. The cost of doing so forces the government to internalize, period by period, the probability of default. In the case of long-term debt, by way of contrast, the evolving probability of default is a cost borne by the creditors rather than by the government. Our paper complements this literature by developing a simple model of sovereign debt maturity, in which short-term debt plays a key role, and by using the model to understand the welfare implications of reforms to the international financial system.

The quantitative literature in this area has also explored the role of dilution in determining the structure

\footnotetext{
${ }^{5}$ In a closed-economy model with full commitment, for instance, Angeletos (2002) and Buera and Nicolini (2004) have shown that, even if the government has access only to non-contingent bonds, it can structure an optimal portfolio of maturities to replicate the hedging properties of contingent bonds.

${ }^{6}$ In a related vein, Debortoli et al. (2014) have recently shown that a government's ability to commit to repayment but not to a path of debt issuance limits its ability to use the maturity structure for hedging purposes.

${ }^{7}$ Of course, there are other motives for why a sovereign may wish to issue short-term debt. Broner, Lorenzoni and Schmukler (2008), for instance, document that the relative cost of long-term borrowing is high for emerging markets and show that this is consistent with the existence of risk-averse creditors. The latter favor short-term debt, thereby making it relatively cheaper and more attractive for governments to borrow in this fashion. See Niepelt (2014) for relevant theoretical results in an infinite horizon model with no government commitment.

${ }^{8}$ Bolton and Jeanne (2009), on the other hand, assume that the government cannot commit to a future path of debt issues which leads, as in our model, to the threat of dilution. Instead of focusing on the maturity structure of government debt, however, they study the optimal mix of debt that is differentially difficult to renegotiate (either fully renegotiable or non-renegotiable). They show that, although the first-best would be to issue only fully renegotiable debt and thus obtain state-contingency, the possibility of dilution forces the government to issue an inefficiently large amount of non-renegotiable debt.
} 
of debt maturity. ${ }^{9} \quad$ Hatchondo et al. (2015) find that the costs imposed by dilution are quantitatively important, in the sense that eliminating the government's ability to dilute existing debt (for instance, though seniority clauses) has a substantial negative effect both on the frequency of defaults and on average spreads. In a related vein, Chatterjee and Eyigungor (2012) find that - absent the possibility of self-fulfilling crises - the costs associated to dilution are high enough to discourage the use of long-term debt altogether and Arellano and Ramanarayanan (2012) show that a calibrated model of endogenous debt maturity can account for the observed relationship between maturity length and the term structure of interest rate spreads in emerging markets. ${ }^{10}$

Our paper contributes three important insights to our understanding of the role of short-term debt. First, it shows that even if short-term debt is issued only for "disciplinary" reasons, countries may find it beneficial to issue more than what would be strictly required for these purposes as there may be trade-off between the total incidence and the severity of debt crises. Second, the paper shows that the welfare consequences of alternative restructuring regimes depend critically on how they affect total expected payments to creditors in these crises episodes. Although these reforms are likely to have important redistributional effects between short- and long-term creditors, we show that these effects are irrelevant from an ex ante perspective. Lastly, the analysis shows that short-term debt may play a novel disciplining role by providing additional incentives for the country to call the IFI in the event of a crisis. In other words, the country may use short-term debt not only as a commitment device to prevent full dilution of long-term debt, but also as a commitment to resort to the IFI when a crisis ensues. This may lead countries to issue more short-term debt in response to some restructuring regimes, even if the regime makes short-term debt more expensive.

The paper proceeds as follows. Section 2 develops the basic model. Sections 3 and 4 characterize the properties of equilibrium. Section 5 introduces the IFI and explores the implications of alternative restructuring regimes. Section 6 provides a general discussion of the results and concludes.

\section{The Model}

In this section we present a model of a country's optimal choice of maturity structure prior to the introduction of an International Financial Institution (IFI). We make several simplifying assumptions (e.g., a finite horizon and two states of nature) that allow us to obtain analytical solutions and to highlight the mechanisms underlying the main results. They key trade-off between short and long-term debt - the former increasing the likelihood of costly crises whereas the latter increasing the scope for dilution - and the analysis of the factors that influence this trade-off should carry through to more complicated environments.

\footnotetext{
${ }^{9}$ To preserve recursivity in an infinite horizon environment the quantitative literature has also made simplifying assumptions (e.g., constant-coupon bonds that mature probabilistically (Chatterjee and Eyigungor (2012), or perpetuities with coupon payments that decay at a geometric rate (Hatchondo and Martinez (2009)).

${ }^{10}$ See also Bai et al. (2014), who extend the quantitative framework to include a country's choice of a growth rate of debt payments.
} 
Consider therefore a model in which time is discrete and there are three periods: $t=0,1,2$. There are two types of agents: a risk-neutral country that is small in world capital markets and perfectly competitive risk-neutral creditors. The country can consume in periods 1 and 2 and discounts future consumption at $\beta=\frac{1}{R}$ where $R>1$ is the gross safe rate of return per period in the international capital market. The country's expected welfare in period 0 is given by

$$
W_{0}=E_{0}\left\{c_{1}+\beta \cdot\left(\left(c_{2}\right)-\pi^{d}(\theta)\right)\right\}
$$

where $\pi^{d}(\theta)$ takes the value $\pi(\theta)$ whenever the country defaults and is zero otherwise, as will be discussed in greater detail below.

In period 0 , the country is endowed with an indivisible productive investment opportunity of size 1 , which matures fully only in period 2. We assume, for simplicity, that the country has no other sources of income and thus the project can only be financed by borrowing. We follow the sovereign risk literature and assume that borrowing is subject to three contracting frictions: it is undertaken through non-contingent bonds; these bonds cannot be renegotiated ex post, in the sense that any failure to meet stipulated payments triggers a default; and, the country cannot commit to a path of future borrowing. ${ }^{11}$

The project requires one unit of investment in period 0 and yields a stochastic return in period 2 . In particular, output in period 2 is given by

$$
y(\theta, k)=\theta \cdot k, \text { for } \theta \in\left\{\theta_{L}, \theta_{H}\right\}
$$

where $\theta$ denotes the productivity of the project (with $\theta_{H}>\theta_{L}$ ) and $0 \leq k \leq 1$ denotes is final size. For simplicity, we set $\theta_{L}=0$. Note that the final size of the project, $k$, can be different from one: the reason is that the project can be interrupted by the country. In particular, as we shall discuss in greater detail below, the country can disinvest a portion $\delta \in[0,1]$ of its project in period 1 . Thus, at the beginning of period 2, the amount of capital remaining in the project is $k=1-\delta$.

Information about the productivity of the project is revealed over time. In period 0 , before accessing capital markets, the probability that $\theta=\theta_{H}$ is given by $p_{0}$. We assume that the net expected present value of the project is positive, i.e., $p_{0} \cdot \theta_{H}>R^{2}$. At the beginning of period 1 , a new signal regarding productivity is received and the updated probability of $\theta=\theta_{H}$ becomes $p \sim G(p)$, where $p \in[0,1]$ and $p_{0}=\int_{0}^{1} p d G(p)$. At the beginning of period $2, \theta \in\left\{\theta_{L}, \theta_{H}\right\}$ is realized. All signals are publicly observed.

To finance the initial unit investment in the project, the country issues short-term (ST) and long-term (LT) bonds in period 0. Each bond promises to pay one unit of the consumption good: ST bonds pay at $t=1$, whereas LT bonds pay at $t=2$. We use $b_{01}$ and $b_{02}$ to respectively denote the quantity of ST and LT bonds issued in period 0 , with $b=\left(b_{01}, b_{02}\right)$, and let $q_{01}$ and $q_{02}$ denote the market price of each type of bond at the time of issuance, with $q=\left(q_{01}, q_{02}\right)$. Thus, financing the project requires satisfying the following budget constraint:

$$
q_{01} \cdot b_{01}+q_{02} \cdot b_{02} \geq 1
$$

\footnotetext{
${ }^{11}$ For a broad discussion of the role of these assumptions in the sovereign debt literature, see Aguiar and Amador (2013).
} 
As we will show later on, bond prices are uniquely determined by the debt structure $b$. This allows us to write $q,(b)=\left(q_{01}(b), q_{02}(b)\right)$, so that the budget constraint depends only on $b$. We henceforth use $T(b)$ to denote the set of debt structures that satisfy this equation, and $T_{1}(b)$ to denote the set of debt structures that do so with equality.

In period 1, after $p$ has been realized, the payment of ST bonds becomes due. At this point, the country can pay these creditors by issuing new bonds $b_{12}$ at a unit price of $q_{12}$ and using the proceeds from this sale. It can also obtain funds by disinvesting from the project. We assume that disinvestment is costly, though. Formally, disinvesting $\delta$ units of capital from the project in period 1, given a signal $p$, yields $F(\delta, p)$ units of output in period 1 where

$$
F(\delta, p)<\delta \cdot \frac{p \cdot \theta_{H}}{R} \text { for } p \in(0,1] \text { with } F(\delta, 0)=0, F_{1}>0, F_{2} \geq 0
$$

Equation (4) implies that disinvestment is inefficient in the sense that it reduces the present value of total output. This assumption is a shorthand for the notion that, in certain times, it may be costly for the country to generate internal resources to pay ST creditors: it may, for instance, need to engage in austerity measures that reduce spending in complementary areas (e.g. cuts in social spending and infrastructure projects), or it may need to engage in excessive taxation that distorts economic activity and reduces potential output. Thus, the country is only able to repay ST creditors in period 1 if

$$
q_{12} \cdot b_{12}+F(\delta, p) \geq b_{01}, \text { for some } \delta \leq 1
$$

In period 2, after $\theta$ has been realized, the payment of all outstanding bonds becomes due. At this point, the country can only pay its creditors by using available output $\theta \cdot k$. Thus, repayment is feasible only in period 2 only if

$$
\theta \cdot k \geq b_{02}+b_{12}
$$

Of course, in order to be able to borrow in equilibrium, the country must not only be able, but also willing, to repay its debts. There are two forces that sustain repayment in the model. First, we assume that creditors can seize the country's output whenever there is a failure to meet stipulated payments. In period 1, we take this to mean that creditors can effectively force the country to engage in disinvestment. In period 2, this means that creditors are able to directly seize output $y(\theta, k){ }^{12}$ Second, we assume that any failure to meet promised payments subjects the country to a non-pecuniary default penalty in period 2: this penalty can be thought of as encapsulating any future losses that a country faces after a default. ${ }^{13}$

\footnotetext{
${ }^{12}$ The model is robust to assuming that only a fraction $\alpha \in(0,1)$ of output or of the project's proceeds can be effectively transferred to creditors. For expositional simplicity we let $\alpha=1$. It is also robust to allowing the country to save any funds obtained from disinvesment (net of the amount paid to creditors) at the international interest rate. These funds could be entirely non-seizable by creditors (see our original nber working paper (2015) for details).

${ }^{13}$ This is a common assumption in the literature. The costs typically emphasized encompass: loss of reputation that reduces trade in goods or assets between the defaulting country and the rest of the world, economic sanctions imposed on the defaulting country by the rest of the world, costs associated to the economic content of defaults, or costs related to domestic holdings of public debt. For a discussion of the theoretical undeprinnings and the empirical evidence, see Borensztein and Panizza (2009) and Sandleris (2012).
} 
Thus, if the country defaults in period 2 when productivity equals $\theta \in\left\{\theta_{L}, \theta_{H}\right\}$, it suffers a penalty equal to $\pi(\theta)$. If the country instead defaults in period 1 , it does not repay anything thereafter and it therefore suffers the default penalty $\pi(\theta)$ in period 2 , for $\theta \in\left\{\theta_{L}, \theta_{H}\right\}$.

It is important to remember that debt cannot be renegotiated: whenever the country is unable to meet stipulated payments, there is a default, creditors obtain funds according to whether default is early (period 1) or late (period 2), and the country suffers the corresponding default penalty. ${ }^{14}$ This implies, in particular, that early default triggers disinvestment even though the latter is inefficient. Atomistic creditors find it individually rational to insist upon repayment instead of renegotiating their debts in a coordinated fashion so as to be paid in period 2 .

The timeline of decisions and realizations is summarized in Figure 1. In brief, in period 0 the country decides its optimal mix of short and long-term bonds, $b=\left(b_{01}, b_{02}\right)$ at market prices $q=\left(q_{01}, q_{02}\right)$. In period 1 , after information about the true state of nature is revealed via $p$, the country decides how much short-term debt to repay, how much to disinvest (required if it is in default) and consume, and the quantity of short-term bonds $b_{12}$ to issue at a unit price $q_{12}$. In period 2 , the state of nature $\theta$ is revealed, payments are made, output is seized if the country is in default, and consumption and any default penalty takes place.

Before turning to the solution of the model, we specify the rules that govern intra-creditor repayment. We assume, as is conventional, that in the event of default all creditors are paid pro rata. If the country is unable to roll-over short term debt in period 1, then it must disinvest. As we will show, this will only occur in equilibrium when complete disinvestment does not suffice to repay creditors. Thus, the entire project will be disinvested to yield $F(1, p)$ and creditors will obtain: ${ }^{15}$

$$
\begin{array}{cc}
\frac{F(1, p)}{b_{01}+b_{02} \cdot R^{-1}} & \text { per ST bond } \\
R^{-1} \cdot \frac{F(1, p)}{b_{01}+b_{02} \cdot R^{-1}} & \text { per LT bond }
\end{array}
$$

If instead the country fails to meet its debt obligations in period 2, then default is declared and all creditors are paid,

$$
\frac{\theta \cdot k}{b_{12}+b_{02}}
$$

per outstanding bond.

\section{$2 \quad$ Feasible Strategies}

In this section we describe the country's feasible strategy set; we solve for the equilibrium strategies in the next section. Periods 0 and 2 are easy to describe. In period 0 the country chooses whether to fund the project and its debt structure $b$. In period 2, if the country has already defaulted in period 1 , the only action available to it is to consume any available income. If the country has not defaulted in period 1, it

\footnotetext{
${ }^{14}$ In particular, creditors are unable to negotiate as a group, forgive debt, or postpone payments, giving rise to a potential role for outside parties (the IFI).

${ }^{15}$ Note that the promised payment to LT creditors is adjusted by $\frac{1}{R}$ in order to reflect repayment in period 1 .
} 
can choose whether to repay its debt obligation if feasible (i.e., if $b_{02}+b_{12} \leq \theta \cdot k$ ) or to default. If full repayment is not feasible, it will necessarily default.

Period 1 has a richer set of feasible strategies, and the rest of this section focuses on it. In this period, the country can always choose to default. It may also be able to avoid default by meeting its ST debt obligations, either by borrowing fresh resources from financial markets (i.e., by rolling over ST debt) or by disinvesting from the investment project. To meet its ST obligations solely through fresh borrowing, the country must raise $q_{12} \cdot b_{12} \geq b_{01}$ from international creditors. When is it feasible for the country to roll-over its ST debt? We distinguish between two cases: repayment of $b_{12}$ by diluting LT creditors and repayment without dilution. Note that if the country does not raise $b_{01}$ in fresh funds, it is required to disinvest.

Given $b=\left(b_{01}, b_{02}\right)$, we can divide the period-1 feasible-strategy space into three basic categories as a function of $p$ : repayment of ST creditors without dilution of LT debt; repayment of ST creditors with dilution of LT debt; and default in period 1.

\subsection{Repayment without Dilution $(p \geq \underline{p})$}

Suppose the country rolls-over its ST debt by borrowing exactly the amount required to repay its ST creditors, i.e., by issuing $b_{12}=\frac{b_{01}}{q_{12}}$ bonds in the credit market at $t=1$. This borrowing does not dilute LT debt (i.e., given $p$, it does not affect the expected value of payments to LT creditors) if and only if $b_{02}+b_{12} \leq \theta_{H}$. In this case, both new creditors and the original LT creditors are repaid fully in period 2 if $\theta=\theta_{H}$, but they are paid nothing otherwise. Thus, the return to LT bonds is unaffected whereas the price of bonds issued in period 1 must satisfy $q_{12}=p / R$.

It follows from this discussion that a necessary and sufficient condition for the country to be able to roll over ST debt without diluting LT debt is that $b_{02}+b_{01} \cdot \frac{R}{p} \leq \theta_{H}$. This allows us to define $\underline{p}(b)$ as the lowest realization of $p$ for which, given a debt structure $b$, it is feasible for the country to roll-over its ST debt and fully repay all creditors in period 2 when $\theta=\theta_{H}$. Formally, $\underline{p}(b)$ is implicitly defined as:

$$
\theta_{H}-b_{02}-b_{01} \cdot \frac{R}{\underline{p}(b)}=0
$$

\subsection{Repayment with Dilution $(p \geq \widehat{p})$}

The other way to roll over ST debt is by diluting the claims of LT creditors. That is, the country may choose to issue so many bonds in period 1 that it affects the expected value of payments to LT creditors. In this case, instead of repaying its LT debt in full in period 2 when $\theta=\theta_{H}$, the country repays $b_{12}$ with a portion of the resources that would have been used to repay LT creditors. This happens whenever $b_{02}+b_{12}>\theta_{H}$ so that the country is certain to default in period 2. Since creditors are paid pro rata in the event of a default, as stipulated in equation (7), it follows that $q_{12}=\frac{1}{R} \cdot \frac{p \cdot \theta_{H}}{b_{02}+b_{12}}$.

Of course, this strategy is compatible with rolling over ST debt if and only if $q_{12} \cdot b_{12} \geq b_{01}$. Otherwise, the country is unable to pay ST creditors and it must default in period 1. Thus, a necessary and sufficient 
condition for the country to roll over ST debt while diluting LT claims is that:

$$
q_{12} \cdot b_{12}=\frac{1}{R} \cdot \frac{p \cdot \theta_{H}}{1+\frac{b_{02}}{b_{12}}} \geq b_{01}
$$

Equation (9) shows that the revenue obtained by issuing bonds in period 1 is decreasing in $p$ and increasing in $b_{12}$. In particular, given a debt structure $b$ and a probability $p$, revenue is maximized by setting $b_{12} \rightarrow \infty$.

In this case, the country's revenue equals $\frac{p \cdot \theta_{H}}{R}$ since it is, in essence, selling period- 1 creditors the total expected value of output. The flip-side of this is that expected payments to LT creditors fall to zero as their claims are fully diluted. Using $\widehat{p}(b)$ to denote the minimum value of $p$ compatible with roll-over via dilution, it follows that

$$
\widehat{p}(b)=\frac{R \cdot b_{01}}{\theta_{H}}
$$

Note that whenever $p>\widehat{p}(b)$ the maximum amount that the country can borrow in period 1 exceeds its outstanding ST debt. In this case, the country can raise enough resources not only to repay ST creditors but also to increase its period- 1 consumption, all at the expense of LT creditors. This, as we will see, creates incentives for debt dilution in equilibrium.

\subsection{Default in period $1(p \geq 0)$}

Lastly, the country can always obtain resources by partially or fully disinvesting from the investment project in period 1 (i.e., by setting $\delta>0$ ). Furthermore, this is the only feasible strategy if $p<\widehat{p}(b)$. For such realizations of $p$, the discounted expected value of output is not enough to repay even ST bonds: this leads ST creditors to demand repayment in period 1 thereby forcing an early default. Although it follows from equation (4) that the output available from divestment, $F(1, p)$, is less than what would be obtained via full dilution, the atomistic nature of creditors implies that the latter cannot agree to collectively roll-over their debt. Each owner of ST debt would find it a dominant strategy to hold out and insist upon early repayment. Note that the same conclusion holds for any amount of disinvestment. Hence, whenever $p<\widehat{p}(b)$, the project is fully disinvested and the country defaults early.

Figure 2 summarizes the feasible period- 1 strategies at each $p$ given $b$. This concludes our description of feasible strategies and we next turn to solving for the equilibrium.

\section{$3 \quad$ Equilibrium Strategies}

In this section we describe the equilibrium strategy of the country. We first solve for equilibrium strategies in period 2 and then work our way backwards. 


\subsection{Final Period $(t=2)$}

In period 2, given its debt promises $b_{02}+b_{12}$, the country maximizes the difference between consumption and default costs. If $\theta=\theta_{L}$, the only feasible strategy for the country is to default. If instead $\theta=\theta_{H}$, since creditors can seize the country's output in the event of default, repayment is optimal for the country whenever possible, i.e., whenever $\theta_{H} \cdot k-b_{02}+b_{12} \geq 0$. After all, any attempt to default would only trigger the corresponding penalty $\pi\left(\theta_{H}\right)$ without increasing its consumption. Thus, the country repays whenever feasible in period 2 .

\subsection{Intermediate Period $(t=1)$}

Suppose first that $p<\widehat{p}(b)$. Then, as explained previously, the only feasible strategy is for the country to default immediately, obtaining an expected payoff of

$$
-\beta \cdot E(\pi(\theta))<0
$$

In this case, the project is fully disinvested, all the output is appropriated by creditors, and the country suffers the corresponding expected value of the default penalty.

If instead $p \in[\widehat{p}(b), \underline{p}(b))$, the country can choose between defaulting immediately or repaying ST debt by diluting LT creditors, thereby postponing the default to period 2 . If the country chooses to dilute LT debt, it is clearly optimal to do so fully by setting $b_{12} \rightarrow \infty .{ }^{16}$ This maximizes its consumption without changing the default penalty. In this case, its expected payoff is given by

$$
\frac{p \cdot \theta_{H}}{R}-b_{01}-\beta \cdot E(\pi(\theta))
$$

From the definition of $\widehat{p}$ in equation (10), this payoff is clearly strictly greater than what the country would obtain by defaulting for $p \in(\widehat{p}, \underline{p})$

Lastly, suppose that the country can repay its ST creditors without diluting LT debt, i.e., $p \geq \underline{p}(b)$, so that the country does not necessarily have to default in period 2 when $\theta=\theta_{H}$. Does the country prefer this option to full dilution? If it borrows just enough to repay ST creditors, the country's payoff is given by:

$$
p \cdot \frac{\left(\theta_{H}-b_{02}\right)}{R}-b_{01}-\beta \cdot(1-p) \cdot \pi\left(\theta_{L}\right)
$$

Comparing the two expressions yields that repayment is preferred to dilution and default if and only if:

$$
b_{02} \leq \pi\left(\theta_{H}\right)
$$

\footnotetext{
${ }^{16}$ In our setup, once the country knows that it will default when $\theta=\theta_{H}$ and pay the corresponding default cost, it finds it optimal to fully appropriate the resources of LT creditors by completely diluting their debt. Thus, partial dilution is never optimal because there is at most one state of nature in which the country may be able to repay. In an economy with various (or a continuum of) possible values of $\theta$, the country's choice of $b_{12}$ would determine both the set of states in which LT debt is diluted as well as the extent of this dilution.
} 
Equation (13), which we henceforth refer to as the incentive-compatibility or IC constraint, is intuitive: it says that repayment dominates dilution if and only if the punishment from default when $\theta=\theta_{H}$ is greater than the gain obtained from diluting LT debt. Full dilution in this case allows the country to appropriate expected payments to LT creditors, $p \cdot b_{02}$, in exchange for an increase in the expected default penalty of $p \cdot \pi\left(\theta_{H}\right)$. Note that the incentive compatibility constraint is thus independent of $p$; the realization of $p$, however, determines whether the choice between repayment or dilution is feasible.

Finally, let us briefly analyze the strategy of disinvesting from the project. We already argued that this is the only feasible strategy when $p<\widehat{p}(b)$. For all other realizations of $p$, disinvestment is clearly suboptimal because it reduces expected output. Hence, if the country is going to default, it is always better to do so by fully diluting LT debt - issuing claims against expected output and consuming early - than by disinvesting from the project.

We can thus summarize the country's optimal strategy in period 1 as follows: if $p<\widehat{p}(b)$, the country is forced to disinvest its project in period 1 and defaults in that period. If $\underline{p}(b)>p \geq \widehat{p}(b)$, the country avoids default in period 1 by fully diluting LT claims. It does so by setting $b_{12} \rightarrow \infty$, thereby defaulting with certainty in period 2. If $p \geq \underline{p}(b)$ and the IC constraint in equation (13) is satisfied, the country borrows just enough to repay ST creditors in period 1 and it repays its entire outstanding bonds in period 2 when $\theta=\theta_{H}$. Finally, if $p \geq \underline{p}(b)$ and the IC constraint is not satisfied, the country follows the same strategy as for $\underline{p}(b)>p \geq \widehat{p}(b)-$ full dilution and default in period 2 .

\subsection{Initial Period $(t=0)$}

We can now determine a country's optimal choice of debt structure $b=\left(b_{01}, b_{02}\right)$. We begin by characterizing the price of ST and LT bonds in period 0. Naturally, these prices incorporate the equilibrium strategies of periods 1 and 2, as characterized in the previous section.

From a creditor's zero-profit condition, we can write $q_{01}(b)$ as

$$
q_{01}(b)=\frac{1}{R} \cdot\left[1-G(\widehat{p}(b))+\int_{0}^{\widehat{p}(b)} \frac{F(1, p)}{b_{01}+b_{02} \cdot R^{-1}} d G(p)\right]
$$

Equation (14) reflects that ST debt is repaid in full whenever $p \geq \widehat{p}$ and is repaid pro rata otherwise. Note that - as we had anticipated $-q_{01}(b)$ depends only on $b$, both directly and indirectly through $\widehat{p}(b)$.

Likewise, we can write $q_{02}$ as

$$
q_{02}(b)=\left\{\begin{array}{cc}
\frac{1}{R} \cdot \int_{0}^{\widehat{p}(b)} \frac{F(1, p)}{b_{01}+b_{02} \cdot R^{-1}} d G(p) & \text { if } b_{02}>\pi\left(\theta_{H}\right) \\
\frac{1}{R^{2}}\left[R \cdot \int_{0}^{\widehat{p}(b)} \frac{F(1, p)}{b_{01}+b_{02} \cdot R^{-1}} d G(p)+\int_{\underline{p}(b)}^{1} p d G(p)\right] & \text { otherwise }
\end{array}\right.
$$

Equation (15) reflects that, if $b_{02}>\pi\left(\theta_{H}\right)$, LT debt is repaid pro rata in the event of full disinvestment; in all other instances, LT debt is fully diluted. If instead $b_{02} \leq \pi\left(\theta_{H}\right)$, equation (15) reflects that LT debt is 
repaid in full only if $p \geq \underline{p}(b)$ and is repaid pro rata when $p<\widehat{p}(b)$. Once again, $q_{02}(b)$ depends only on $b$, both directly and indirectly through $\widehat{p}(b)$ and $p(b) .{ }^{17}$

Given any debt structure $b$, equations (8) and (10) determine the threshold probabilities $\widehat{p}(b)$ and $\underline{p}(b)$, whereas equations (14) and (15) determine bond prices $q=\left(q_{01}(b), q_{02}(b)\right)$. We can then use these, along with the budget constraint of equation (3), to define the set $b \in T_{1}(b)$ of debt structures that enable the country to raise just enough funds to undertake the investment project. The optimal choice of the country is then to select among such structures. Formally, the country solves:

$$
\begin{aligned}
\max _{b \in T_{1}(b)} W_{0}(b) & =\int_{0}^{\widehat{p}(b)} F(1, p) \cdot d G(p)+\beta \cdot\left[\int_{\widehat{p}(b)}^{1} p \theta_{H} d G(p)-\int_{0}^{\underline{p}(b)} p \pi\left(\theta_{H}\right) d G(p)-\left(1-p_{0}\right) \cdot \pi\left(\theta_{L}\right)\right]-R(16) \\
\text { s.t. } W_{0}(b) \geq 0 & \geq
\end{aligned}
$$

where constraint that $W_{0}(b) \geq 0$ reflects the country's outside option of setting $b_{01}=b_{02}=0$ and not investing in the project. Note that maximizing welfare amounts to minimizing instances of disinvestment, i.e., $\widehat{p}(b)$, and of default, i.e. $\underline{p}(b)$. It is useful to note for future purposes that $\widehat{p}$ is solely a function of $b_{01}$, whereas $\underline{p}$ is a function of the entire maturity structure.

We are now ready to analyze the country's optimal choice of debt structure. Crucially, the IC constraint of equation (13) is incorporated into the price of LT bonds through equation (15). This must be kept in mind because it may limit the country's use of LT bonds even though these are in principle desirable. To see this, we first analyze the optimal choice of debt structure in the absence of dilution, i.e., when the country can commit to a particular path of debt and is therefore not subject to the IC constraint. We then return to the original model.

\subsubsection{Optimal choice of debt structure without dilution}

Suppose the country could commit to not issuing any bonds in period 1, i.e., to setting $b_{12}=0$ for all realizations of $p$. In this case, the country would not be subject to the IC constraint and the price of LT bonds would be given by

$$
q_{02}(b)=\frac{1}{R^{2}} \cdot\left[R \cdot \int_{0}^{\hat{p}(b)} \frac{F(1, p)}{b_{01}+b_{02} \cdot R^{-1}} d G(p)+\int_{\underline{p}(b)}^{1} p d G(p)\right] \text { for } b_{02} \geq 0 .
$$

The rest of the optimization problem remains unchanged, and it is easy to see that the optimal debt structure would entail setting $b_{01}=0$ and funding the project entirely with LT debt. Consequently, $\underline{p}=0$ and the country repays LT creditors in full whenever $\theta=\theta_{H}$. Hence $q_{02}=\frac{p_{0}}{R^{2}}$ and thus $b_{02}=\frac{R^{2}}{p_{0}}$. Equilibrium

\footnotetext{
${ }^{17}$ As anticipated, we are ignoring all equilibria that arise solely as a result of negative self-fulfilling expectations (e.g., all ST creditors refusing to roll over their debt because they expect other ST creditors to do the same). These are well-understood and are easy to incorporate in the analysis.
} 
welfare is in turn given by

$$
W_{0}\left(0, \frac{R^{2}}{p_{0}}\right)=\frac{p_{0} \theta_{H}-\left(1-p_{0}\right) \cdot \pi_{L}}{R}-R
$$

The interpretation of equation (17) is clear. When the country can commit to not diluting LT bonds, it does not need to borrow short-term and it therefore eliminates all possibility of default in period 1. There is no disinvestment in equilibrium and the country's expected welfare equals the discounted value of expected output net of the cost of funds and the costs of default when $\theta=\theta_{L}$. These costs originate in the non-contingent and non-renegotiable nature of bonds and thus they cannot be avoided.

With this benchmark in mind, we now characterize the optimal debt structure in the original model.

\subsubsection{Optimal choice of debt structure}

Can the country fund itself entirely with LT debt in the absence of commitment? Only if the IC constraint is satisfied, i.e. if and only if $\frac{R^{2}}{p_{0}}<\pi\left(\theta_{H}\right)$. If not, creditors correctly anticipate that the country will fully dilute LT bonds in period 1 and $q_{02}=0$. We henceforth focus on this case by assuming

$$
R^{2}>p_{0} \pi\left(\theta_{H}\right)
$$

which guarantees that any equilibrium with positive debt requires some measure of ST bonds.

We can easily characterize several essential properties of the optimal maturity structure of debt, $b^{*}=$ $\left(b_{01}^{*}, b_{02}^{*}\right)$. First, $b^{*}$ must respect the incentive compatibility constraint of equation $(13)$, i.e., $b_{02}^{*} \leq \pi\left(\theta_{H}\right)$. To understand why, note that - once the IC constraint is violated - the marginal revenue of LT debt is zero. In order for its marginal revenue to be positive, LT debt must increase total expected payments to creditors. But this cannot not happen if the IC constraint is violated: if $p \geq \widehat{p}$, LT debt is fully diluted; if instead $p<\widehat{p}$, there is full disinvestment and total payments to creditors equal $F(1, p)$ regardless of the amount of debt issued. Thus, any amount of LT debt above the IC constraint serves only to increase $\underline{p}(b)$ without generating any additional revenue, while $\widehat{p}$ is unaffected as it is solely a function of $b_{01}$. Second, it is possible that the country is unable to fund the project in period 0 , despite its positive net present value, as a result of the IC constraint. In this case, the set $T_{1}(b)$ is empty. A sufficient condition to rule out this possibility is that there exists $\left(b_{01}, 0\right) \in T_{1}(b)$ for some $b_{01}$, so that the project can be funded solely by issuing ST debt.

Equation (16) also illustrates the trade-offs associated with the use of ST and LT debt. Relative to the model without dilution in which only LT debt is issued in equilibrium, the use of ST leads to costly debt crises. These crises take place for all $p<\underline{p}(b)$ : when $p<\widehat{p}(b)$, they are resolved through inefficient disinvestment and early (period-1) default; when $p \in[\widehat{p}(b), p(b))$, they are instead resolved through dilution and late (period-2) default. The country would thus like to choose the debt structure $b \in T_{1}(b)$ that minimizes both thresholds. There is a potential trade-off, however, because $\widehat{p}(b)$ is unambiguously increasing in $b_{01}$ but the relationship between $\underline{p}(b)$ and $b_{01}$ is ambiguous. The reason for the ambiguity is that $q_{02}<\frac{q_{01}}{R}$ (i.e., LT creditors are repaid in fewer states than ST creditors), which makes LT debt expensive. This implies that substituting ST debt for LT debt so as to keep revenue constant may reduce the overall likelihood of a crisis 
$G(\underline{p}(b))$, even though it increases the likelihood that a crisis - when it occurs - is more severe (i.e., it will involve disinvestment) $G(\widehat{p}(b))$. As a result, a country's optimal debt structure may lie in the interior of the IC constraint (i.e., $b_{02}^{*}<\pi\left(\theta_{H}\right)$ ). We relegate a formal proof of this statement to the appendix, but we provide a graphical discussion in what follows.

In Figure 3, the vertical and horizontal axis respectively represent the quantity of ST and LT bonds issued by the country, $b_{01}$ and $b_{02}$. The $T_{1}(b)$ locus represents the combinations of ST and LT bonds that enable the country to borrow one unit in period 0 . This locus need not be continuous, but it is depicted as such for simplicity. The downward-sloping lines represent "iso- $\underline{p}$ loci," i.e., combinations of $b_{01}$ and $b_{02}$ for which $\underline{p}(b)$ is constant. Among these loci, $\underline{p}$ decreases as the debt structure moves towards the origin.

The country's optimization problem can be thought of as the choice of a point on the $T_{1}(b)$ locus that optimally combines low values of $b_{01}$, and thus of $\widehat{p}(b)$, with low values of $\underline{p}(b)$. Panels I and II of Figure 4 illustrate the two possibilities that may arise. In panel I, $\underline{p}(b)$ decreases as the maturity structure is lengthened along the $T_{1}(b)$ locus. Thus, the country minimizes both $\widehat{p}(b)$ and $\underline{p}(b)$ by choosing a debt structure like the one depicted by point A, which lies on the IC constraint and thus has $b_{02}=\pi\left(\theta_{H}\right)$. Panel II illustrates instead a case in which LT debt is relatively expensive and - at least locally $-\underline{p}(b)$ increases as the maturity structure is lengthened along the $T_{1}(b)$ locus. In this case, the country faces a trade-off between minimizing $\widehat{p}(b)$, which requires a longer maturity structure, and minimizing $\underline{p}(b)$, which requires a shorter maturity structure. Consequently, a debt structure like the one depicted by point $\mathrm{B}$, in which $b_{02}<\pi\left(\theta_{H}\right)$ and the IC constraint is slack, may be optimal. This example illustrates how, even if the only role of ST debt is to control dilution, the country may find it beneficial to issue more of it than what would be strictly necessary for this purpose because there is trade-off between the total incidence and the severity of debt crises.

This completes the characterization of the equilibrium maturity structure of debt. The general message is that, when a country is unable to commit to not dilute LT debt, the maturity structure shortens relative to what it would otherwise be. This is costly because debt contracts are non-contingent and renegotiation is not possible (or efficient), so that ST debt exposes the country to costly crises and inefficient repayments whenever the economic outlook is bleak. We next use this model to evaluate the role of an international financial institution such as the IMF and to explore the merits of debt restructuring or reprofiling in the event of a crisis.

\section{A Role for an IFI}

The model features two imperfections that potentially can be addressed by an IFI. The first, and most obvious one, is the lack of coordination among ST creditors. This forces the country to engage in inefficient disinvestment in order to repay its creditors in period 1 when $p$ is below $\widehat{p}$. In this situation, it is clear that halting repayments would be efficiency enhancing ex post. How would such a policy affect ex ante welfare? 
The second potential problem that an IFI may be able to address concerns the dilution of LT creditors. Although there are no ex post inefficiencies associated with dilution - it simply redistributes future output from LT creditors to the country - it is costly, from an ex ante perspective, as it forces the country to issue more debt to raise a unit of revenue. This increases the instances of default with or without disinvestment. How would a policy that addressed dilution affect welfare? Would a country ever find such a policy desirable?

To answer these questions, we modify the benchmark model to include an IFI as follows. After observing $p$ in period 1 , the country decides whether to approach the IFI for help. The IFI then decides whether to intervene, given the set of policy tools at its disposal. We assume that the IFI maximizes the equally weighted sum of creditor and country welfare. Hence, it is not concerned with redistribution per se, neither between the country and its creditors nor within the group of creditors. Because preferences are linear, this amounts to the IFI having the objective of maximizing expected output net of default costs - a useful benchmark. ${ }^{18}$ Furthermore, we model the IFI as having the same commitment technology as the country: it cannot commit to a policy rule in advance.

\subsection{Restructuring}

We start by defining a restructuring regime. A restructuring regime is a set of rules that: i. Guides interventions in period 1 after $p$ is known, but only if country calls in the IFI; ii. Halts all payments to creditors at $t=1$; iii. Postpones all payments to $t=2$, and changes the total amounts due to $D^{r}(p) \leq \theta_{H}$ and its division between ST and LT bond holders to $b^{\prime}(p)=\left(b_{01}^{\prime}(p) R, b_{02}^{\prime}(p)\right)$ such that $D^{r}(p)=b_{01}^{\prime}(p) R+$ $b_{02}^{\prime}(p)$; iv. Prevents the country from taking on additional debt in period 1.

Next we analyze the consequences of alternative restructuring policies. We often refer to a restructuring as being imposed by the IFI although in reality such an agreement requires complicated negotiations among creditors, country, and the IFI. ${ }^{19}$ In this model we abstract from this procedure and instead discuss the implications of different restructuring outcomes. It is important to note, however, that for a given $p$, the restructuring outcome requires the willingness both of the country to call in the IFI and of the IFI to restructure and is thus an equilibrium outcome. Thus, this limits restructuring outcomes to those that enhance ex post efficiency and that do not decrease the country's ex post welfare.

Before analyzing the equilibrium consequences of restructuring regimes, it is instructive to study an exogenously imposed restructuring regime. That is, one that is in place and applied independently of the desires of the country or of the IFI. The next proposition is central to the paper's welfare results. Henceforth, all variables with an $r$ superscript refer to those with a known restructuring regime $r$ in place, whereas variables without a superscript refer to the equilibrium outcomes in the absence of a restructuring regime.

\footnotetext{
${ }^{18}$ In Section 6, we briefly discuss the effects of relaxing this assumption.

${ }^{19}$ See Yue (2010) for a model of sovereign debt renegotiation.
} 
Proposition 1 Suppose that at $t=0$, prior to the country's debt maturity decision, a particular restructuring regime $r$ is in place. This regime restructures debt exogenously (i.e., independently of the country and IFI) whenever $p \leq \widetilde{p}^{r}(b)$, for some arbitrary $\widetilde{p}^{r}(b) \in(0, \underline{p}(b)), \forall b$. At each $p \leq \widetilde{p}^{r}(b)$, all period 1 payments are halted, no new debt is incurred, and total debt is restructured and written down to $D^{r}(p)=$ $b_{01}^{\prime}(p) \cdot R+b_{02}^{\prime}(p) \leq \theta_{H}$. Suppose that

$$
\int_{0}^{\widetilde{p}^{r}(b)} p \cdot \frac{D^{r}(p)}{R} d G \geq \int_{0}^{\widehat{p}(b)} F(1, p) d G+b_{01} \cdot\left(1-G\left(\widetilde{p}^{r}(b)\right)\right)
$$

i.e., this intervention does not decrease the expected value of total payments to creditors over the interval $\left(0, \widetilde{p}^{r}(b)\right)$, though it may change its distribution. It follows that $b \in T(b) \Rightarrow b \in T^{r}(b)$.

Proof. Note that, for each $b=\left(b_{01}, b_{02}\right), \widehat{p}^{r}(b)=\widehat{p}(b)$ and $\underline{p}^{r}(b)=\underline{p}(b)$. Thus total expected payments to creditors are unchanged above $\underline{p}(b)$ and, by assumption, they are no smaller below $\widetilde{p}^{r}(b)$. For $p \in$ $\left(\widetilde{p}^{r}(b), \underline{p}(b)\right)$, the country's optimal strategy remains unchanged: if $\widetilde{p}^{r}(b)<\widehat{p}(b)$, the country continues to default in period 1 for $p \in\left(\widetilde{p}^{r}(b), \widehat{p}(b)\right)$ and completely dilute LT creditors for $p \in[\widehat{p}(b), \underline{p}(b))$. If instead $\widetilde{p}^{r}(b) \geq \widehat{p}(b)$ then the country continues to dilute LT debt for $p \in\left[\widetilde{p}^{r}(b), \underline{p}(b)\right)$. Thus, payments to creditors are unchanged in this interval as well. Hence, this exogenously imposed restructuring regime must raise at least as much revenue at $t=0$ as without restructuring. That is,

$$
\begin{aligned}
q_{01}(b) \cdot b_{01}+q_{02}(b) \cdot b_{02} & =\int_{0}^{\widehat{p}(b)} \frac{F(1, p)}{R} d G+\frac{b_{01}}{R} \cdot[1-G(\widehat{p}(b))]+\int_{\underline{p}(b)}^{1} p \cdot \frac{b_{02}}{R^{2}} d G \\
& \leq \\
q_{01}^{r}(b) \cdot b_{01}+q_{02}^{r}(b) \cdot b_{02} & =\int_{0}^{\widehat{p}^{r}(b)} p \cdot \frac{D^{r}(p)}{R^{2}} d G+\frac{b_{01}}{R} \cdot\left[1-G\left(\widehat{p}^{r}(b)\right)\right]+\int_{\underline{p}(b)}^{1} p \cdot \frac{b_{02}}{R^{2}} d G
\end{aligned}
$$

where the inequality follows from equation (19). Thus, $b \in T(b) \Longrightarrow b \in T^{r}(b) . \mid$

The proposition above is very powerful. It shows that how repayments are distributed across creditors in times of crisis is irrelevant to the feasibility of a particular bond maturity structure, i.e., to whether that maturity structure is capable of raising at least a unit of revenue. All that matters is the total expected value of these payments, not their distribution. A potentially important assumption, however, was the exogenous nature of the imposition of the restructuring regime. We next turn to examining whether the two relevant parties - the county and the IFI - will want to accept a particular restructuring plan.

Consider first the IFI's willingness to restructure debt in period 1. Since the IFI maximizes expected output net of default costs, it will be willing to restructure whenever $p<\widehat{p}$. By doing so, it prevents disinvestment and increases the resources available to distribute between the country and its creditors in period 2. For $p \in[\widehat{p}, \underline{p})$, on the other hand, debt restructurings redistribute resources without affecting efficiency. Thus, in those cases the IFI would choose not to intervene even if the country desired it. ${ }^{20}$ The country, in turn, is always willing to call the IFI when $p<\widehat{p}$, since it can only be made better off

\footnotetext{
${ }^{20}$ Even an arbitrarily small cost of intervention would make the IFI strictly prefer not to intervene. Of course, the IFI would not intervene when there is no crisis either, $p \geq \underline{p}$, as this imposes a default cost on the country and thus decreases total welfare.
} 
by preventing disinvestment. It thus follows that debt payments are restructured in equilibrium whenever $p<\widehat{p}$. A country's ex ante welfare under restructuring is thus given by:

$$
W_{0}^{r}(b)=\beta \cdot \int_{0}^{1} p \cdot \theta_{H} d G(p)-\beta \cdot \int_{0}^{\underline{p}^{r}(b)} p \cdot \pi\left(\theta_{H}\right) d G(p)-\beta \cdot\left(1-p_{0}\right) \cdot \pi\left(\theta_{L}\right)-R
$$

Below we provide a sufficient condition for such restructurings to increase ex ante welfare.

Proposition 2 Consider a debt restructuring regime $r$. A sufficient condition for $r$ to increase ex ante welfare is $\int_{0}^{\widehat{p}(b)} p \cdot \frac{D^{r}(p)}{R} d G \geq \int_{0}^{\widehat{p}(b)} F(1, p) d G, \forall b \in T_{1}(b)$.

Proof. We have already established that both the country and the IFI will be willing to implement, ex post, such a regime for any $p<\widehat{p}^{r}(b)$. Take any $b \in T_{1}(b)$. Note that $\widehat{p}^{r}(b)=\widehat{p}(b)$ as $\widehat{p}$ is only a function of $b_{01}$. Note next that, by Proposition $1, b \in T^{r}(b)$. Thus, for each $b \in T_{1}(b)$, if expected payments under restructuring are strictly greater than before, the country can lower LT bonds to $b_{02}^{r}<b_{02}$ such that the revenue raised is once again equal to $1 .{ }^{21}$ This implies $\underline{p}^{r}\left(b_{01}, b_{02}^{r}\right)<\underline{p}\left(b_{01}, b_{02}\right)$. If, instead, total expected payments to creditors under restructuring are equal to those without restructuring, the country sets $b_{02}^{r}=b_{02}$, and thus $\underline{p}^{r}\left(b_{01}, b_{02}^{r}\right)=\underline{p}\left(b_{01}, b_{02}\right)$. In both cases the country's ex ante welfare strictly increases since

$$
W_{0}^{r}\left(b_{01}, b_{02}^{r}\right)-W_{0}\left(b_{01}, b_{02}\right)=\beta \cdot \int_{0}^{\widehat{p}\left(b_{01}\right)}\left[p \cdot \theta_{H}-R \cdot F(1, p)\right] d G(p)+\beta \cdot \int_{\underline{p}^{r}\left(b_{01}, b_{02}^{r}\right)}^{\underline{p}\left(b_{01}, b_{02}\right)} p \cdot \pi\left(\theta_{H}\right) d G(p)
$$

which is strictly positive since $p \cdot \theta_{H}>R \cdot F(1, p)$ and $\underline{p}^{r}\left(b_{01}, b_{02}^{r}\right) \leq \underline{p}\left(b_{01}, b_{02}\right) \cdot \|$

The intuition for this result is clear. Restructuring strictly increases a country's ex ante welfare by halting inefficient disinvestment in the event of a crisis. This is captured by the first integral in equation (20). But it also changes expected payments to creditors by writing down the total debt. If expected payments fall as a result of restructuring, bond prices decrease at $t=0$ and the country needs to issue more debt in order to fund the project. This leads to an increase in $\underline{p}$ and, consequently, in the expected costs of default, which could overturn the welfare gains of avoiding disinvestment. In terms of equation (20), the second integral could be negative. A sufficient condition for $\underline{p}$ not to increase, and thus for restructuring to be Pareto improving, is that expected total payments to creditors over $(0, \widehat{p})$ not fall.

Corollary 1 A restructuring regime $r$ that does not change total expected payments to creditors over $\left(0, \widehat{p}^{r}(b)\right)$ (i.e., $\int_{0}^{\widehat{p}(b)} p \cdot \frac{D^{r}(p)}{R} d G=\int_{0}^{\widehat{p}(b)} F(p, 1) d G \forall b$ ), leaves the country's optimal choice of $b$ unchanged.

Proof. If restructuring does not change total expected payments to creditors, then it does not change $T(b)$ and hence whichever maturity structure was optimal without restructuring remains optimal with it.|

\footnotetext{
${ }^{21}$ If, when $b_{02}^{r}$ is set to zero, revenue still exceeds 1 , then the country can decrease $b_{01}$ as well. This too increases its ex ante welfare.
} 
We can return to Figure 3 to illustrate why the corollary holds. A policy that doesn't change total expected payments when debt is restructured leaves the $T_{1}(b)$ locus unchanged. Since the iso- $\underline{p}$ loci are also unaffected by restructuring policies, it follows that the country's optimal debt structure is also unchanged. Note that the country is still better off: it increases its consumption because restructuring eliminates disinvestment, but the incidence of default remains the same.

Corollary 2 Consider two restructuring regimes, $x$ and $v$. Suppose $\int_{0}^{\widehat{p}(b)} p \frac{D^{x}(p)}{R} d G>\int_{0}^{\widehat{p}(b)} p \frac{D^{v}(p)}{R} d G \forall b$. It follows that ex ante welfare is higher under $x$ than under $v$.

Proof. Let $b^{v}=\left(b_{01}^{v}, b_{02}^{v}\right)$ be the optimal maturity structure under $v$. Consider regime $x$ but with maturity structure $b=b^{v}$ and hence with $\widehat{p}^{x}(b)=\widehat{p}^{v}(b)=\widehat{p}(b)$. Expected payments to creditors will be higher under $x$ than under $v$ and hence $b^{v}$ yields the country more than one unit of revenue at $t=0$. This implies that the country can decrease $b_{02}$ to $b_{02}^{x}<b_{02}^{v}$ so that $\left(b_{01}^{v}, b_{02}^{x}\right) \in T_{1}^{x}(b)$. It follows that $\underline{p}^{x}\left(b_{01}^{v}, b_{02}^{x}\right)<\underline{p}^{v}\left(b_{01}^{v}, b_{02}^{v}\right)$, strictly increasing ex ante welfare.||

This completes our discussion of restructuring. As shown, the way in which restructuring divides payments across creditors is irrelevant to ex ante welfare. Although different divisions of a given total amount of payments affect ex ante bond prices, they do not affect the capacity of a given bond maturity structure to fund the project. Only total expected payments to creditors matter. The more generous a restructuring regime is to creditors ex ante, the greater will be the country's ex ante welfare gain.

Next we analyze a new policy proposed by the IMF: reprofiling. The latter is considered a light type of restructuring that extends the maturity of any outstanding debt that is due within a specific window of time such that, if the country's outlook improves in the near future, this debt can be repaid. In our model, this policy is easily translatable as a restructuring that rolls over ST debt in period 1 at a rate that ensures that, if $\theta=\theta_{H}$, the country is able to repay its debts in period 2 .

With no further modifications, the results of Proposition 2 apply here as well. Both the IFI and the country would be willing to reprofile debt whenever $p<\widehat{p}$ and this regime would be guaranteed to increase ex ante welfare if expected payments to creditors did not fall. Neither the country nor the IFI would want to intervene for $p \geq \widehat{p}$. There would be no new benefit associated with this policy. The IMF has argued, however, that although reprofiling is a credit event, the associated default cost should be smaller than before as only some fraction of the debt is being restructured (see IMF (2014b)). ${ }^{22}$ We now analyze the welfare consequences given this assumption.

\subsection{Reprofiling}

Formally, let $R^{f}(p ; b)$ denote the implicit rate at which ST debt is rolled over under reprofiling. Note that $R^{f}(p ; b)<\frac{R}{p}$, i.e., in order to allow the country to avoid defaulting in period 2 when $\theta=\theta_{H}$, re-

\footnotetext{
${ }^{22}$ IMF (2014b) provides suggestive evidence that, in practice, reprofilings do seem to be less costly than debt restructurings.
} 
profiling must necessarily impose a "haircut" on ST creditors. ${ }^{23}$ Suppose that, at each $p$, total debt is restructured to $D^{f}(p) \leq \theta_{H}$. It follows that the implicit rate that ST creditors are receiving is $R^{f}(p)=$ $\max \left\{\frac{D^{f}(p)-b_{02}}{b_{01}}, 0\right\}$ or, stated differently, $b_{01}^{\prime}(p) \cdot R+b_{02}^{\prime}(p) \equiv D^{f}(p)$ with $b_{02}^{\prime}(p)=\min \left\{b_{02}, D^{f}(p)\right\}$ and $b_{01}^{\prime}(p)=\max \left\{\frac{D^{f}(p)-b_{02}}{R}, 0\right\}$.

Assume that reprofiling entails a lower penalty than either a conventional restructuring or an outright default. In particular, suppose that a country that reprofiles its debts incurs the default $\operatorname{cost} \pi^{f}\left(\theta_{H}\right)$ $<\pi\left(\theta_{H}\right)$ in period 2 , for $\theta=\theta_{H} \cdot{ }^{24}$ For which realizations of $p$ would the IFI want to intervene? And, for which realizations of $p$ would the country call the IFI? Note that, in addition to the efficiency gain that results from avoiding disinvestment in period 1 for $p<\widehat{p}$, reprofiling entails - by assumption - an additional efficiency gain in the form of a lower default penalty. Hence, the IFI is willing to reprofile the debt whenever $p<\underline{p}$. The country instead faces a trade-off for $p \geq \widehat{p}$. On the one hand, it gains from a lower default penalty if it reprofiles. On the other hand, however, it loses its ability to dilute LT creditors and thereby increase its own consumption. Hence, the country will only approach the IMF when the gains of reprofiling exceed those of dilution.

Formally, determining the range of $p \geq \widehat{p}$ for which reprofiling takes place in equilibrium requires comparing the country's payoff from reprofiling

$$
p \cdot \theta_{H}-p \cdot D^{f}(p)-p \cdot \pi^{f}\left(\theta_{H}\right)-(1-p) \cdot \pi\left(\theta_{L}\right)
$$

with its payoff in the absence of IFI intervention

$$
p \cdot \theta_{H}-b_{01} \cdot R-p \cdot \pi\left(\theta_{H}\right)-(1-p) \cdot \pi\left(\theta_{L}\right),
$$

which yields that reprofiling is preferred by the country if and only if

$$
p \cdot D^{f}(p) \leq b_{01} \cdot R+p \cdot\left(\pi\left(\theta_{H}\right)-\pi^{f}\left(\theta_{H}\right)\right)
$$

Let $\mu\left(p ; D^{f}(p), b_{01}\right)$ denote the set of $p \in(\widehat{p}, \underline{p})$ that satisfy the country's (as well as the IFI's) ex post incentive compatibility constraint of equation (21). Note that this set shrinks with $D^{f}(p)$ and expands with the difference between $\pi$ and $\pi^{f}$. The intuition for this is clear: to reprofile its debt and surrender its benefits from dilution, the country must be "bribed" either through a lower default penalty or through lower expected payments to creditors. On the other hand, as will be demonstrated in the proposition below, the sufficient condition for reprofiling to raise ex ante welfare is that the expected value of these payments not fall, creating a tension between ex post and ex ante welfare.

It is clear that reprofiling debt dominates other forms of debt restructuring for any given $D^{f}(p)=$ $D^{r}(p)$ for $p<\widehat{p}(b)$ since, by assumption, it incurs a lower default cost and the country's ex post incentive

\footnotetext{
${ }^{23}$ As with restructuring, in an environment with many values of $\theta$ the choice of $R^{f}(p)$ would more generally imply a choice regarding the range of $\theta$ which would result in default in period 2.

${ }^{24}$ If $\theta=\theta_{L}$, the country will default regardless of the rate at which ST debt has been reprofiled. We thus assume, for simplicity, that the country still faces the penalty $\pi\left(\theta_{L}\right)$.
} 
compatibility constraint is not violated. So, in what follows we will restrict our attention to $p \in[\widehat{p}(b), \underline{p}(b))$. The following proposition provides a sufficient condition for reprofiling to improve ex ante welfare in this range.

Proposition 3 Consider any debt reprofiling regime $f$ restricted to $\widehat{p}^{f}(b)<p<\underline{p}^{f}(b), \forall b$. A sufficient condition for this regime to increase ex ante welfare is

$$
\int_{\mu(p)} p D^{f}(p) d G \geq \int_{\mu(p)} b_{01} R d G \quad \forall b
$$

where $\mu\left(p ; D^{f}(p), b_{01}\right)=\left\{p: p D^{f}(p) \leq b_{01} R+p\left(\pi\left(\theta_{H}\right)-\pi^{f}\left(\theta_{H}\right)\right)\right\}$.

Proof. The set $\mu$ consists of those $p$ that are consistent with the country calling the IFI in period 1 and the IFI reprofiling the debt in a particular way (i.e., they satisfy equation $(21))$. For a given $b, \widehat{p}(b)$ and $\underline{p}(b)$ do not change as a result of reprofiling, i.e., $\widehat{p}^{f}(b)=\widehat{p}(b)$ and $\underline{p}^{f}(b)=\underline{p}(b)$. Hence, if $p \notin \mu\left(p ; D^{f}(p), b_{01}\right)$, the country's strategy, and thus payments to creditors, are unchanged. For $p \in \mu\left(p ; D^{f}(p), b_{01}\right)$, equation (22) guarantees that expected payments to creditors don't fall for these $p$ either. Hence, by Proposition (1), if $b \in T(b) \Rightarrow b \in T^{f}(b)$. We can then proceed as in the proof of Proposition (2): if the inequality in equation (22) is strict, then total expected payments to creditors are strictly greater with reprofiling and the country can choose $b_{02}^{f}<b_{02}$ such that $\left(b_{01}, b_{02}^{f}\right) \in T_{1}^{f}(b)$. It follows that $\underline{p}^{f}\left(b_{01}, b_{02}^{f}\right)<\underline{p}\left(b_{01}, b_{02}\right)$, strictly increasing ex ante welfare. If expected total payments are unchanged, then the original $b$ still raises one unit of revenue. In both cases, the country's change in expected welfare from reprofiling is given by

$$
W_{0}^{f}\left(b_{01}, b_{02}^{f}\right)-W_{0}\left(b_{01}, b_{02}\right)=\beta \cdot \int_{\underline{p}^{f}\left(b_{01}, b_{02}^{f}\right)}^{\underline{p}\left(b_{01}, b_{02}\right)} p \cdot \pi\left(\theta_{H}\right) d G(p)+\beta \cdot \int_{\mu\left(p ; D^{f}(p), b_{01}\right)} p \cdot\left[\pi\left(\theta_{H}\right)-\pi^{f}\left(\theta_{H}\right)\right] d G(p)
$$

This expression is strictly positive since $\pi\left(\theta_{H}\right)-\pi^{f}\left(\theta_{H}\right)>0$ and $\underline{p}^{f}\left(b_{01}, b_{02}^{f}\right) \leq \underline{p}\left(b_{01}, b_{02}\right) . \|$

Note that the sufficient condition for reprofiling to increase ex ante welfare is very similar to the one provided for restructuring. Both say that ex ante welfare gains are guaranteed if these regimes do not distribute all the gains (payments) to the country. The added twist in the case of reprofiling is the endogeneity of the states in which the country will be willing to have its debt reprofiled. A simple corollary follows.

Corollary 3 If $\pi\left(\theta_{H}\right)=\pi^{f}\left(\theta_{H}\right)$, a debt reprofiling regime restricted to $p \in\left(\widehat{p}^{f}(b), \underline{p}(b)\right)$ can only decrease ex ante welfare.

Proof. If $\pi\left(\theta_{H}\right)=\pi^{f}\left(\theta_{H}\right)$, then for each $b \in T_{1}(b)$ either $\mu\left(p ; D^{f}(p), b_{01}\right)$ is empty or, if not, expected total repayments to creditors for $p \in \mu(p ; b)$ are weakly lower than without reprofiling. If payments are the same, then if $b \in T_{1}(p) \Rightarrow b \in T_{1}^{f}(p)$. If expected total payments to creditors are strictly lower for a positive measure of $p \in \mu\left(p ; D^{f}(p), b_{01}\right)$, then if $b \in T_{1}(p) \Rightarrow b \notin T^{f}(p)$ and the country may need to change its maturity structure. Thus $T^{f}(p) \subseteq T(p)$, which can only decrease ex ante welfare.|| 
As shown in this section, a reprofiling regime is guaranteed to increase expected welfare if it does not decrease expected payments to creditors when actually used. The tension lies in fulfilling this condition without eliminating the country's incentive to actually call the IFI. One way in which the country can decrease this tension is by adopting a shorter debt maturity than would otherwise be optimal. This is illustrated in equation (21), which shows that - for a given $D^{f}(p)$ - increases in ST debt expand the set $\mu\left(p ; D^{f}(p), b_{01}\right)$ because they reduce the country's gain from dilution (its ability to consume the difference between $p \theta_{H}$ and $b_{01} R$ ). Thus, somewhat paradoxically, although ST bonds may become more expensive as a result of a policy that places most of the burden of adjustment short-term creditors, the country may find it optimal to increase its reliance on ST debt in order to provide itself with greater incentives to call the IFI.

\section{$5 \quad$ Discussion and Concluding Remarks}

There has been much discussion recently regarding the resolution of sovereign debt crises. Much of it has centered on how to restructure debt, either by extending the maturity of some portion of debt (reprofiling) or via outright haircuts. This paper provides an analytical framework in which to think about the consequences of different restructuring regimes and the role of debt maturity.

In our framework short-term debt plays two roles: on the one hand it increases the incidences of debt crises by making the country more susceptible to roll-over crises when there is bad news about the country's future prospects. On the other hand, as in much of the recent literature on sovereign debt maturity, it plays a crucial disciplining role. In our model it reduces the incentive to dilute long-term debt. The model highlights two potential ways in which restructuring regimes can mitigate the negative consequences of debt crises. They can halt disinvestment, which is driven by a coordination failure among atomistic creditors, and they can diminish the incentive to dilute long-term debt, which is driven by the country's inability to commit to a certain path of debt in advance.

In this paper we ask whether the expected treatment of short- versus long-term debt during a restructuring/reprofiling episode matters. Despite the critical role played by short-term debt, we find the redistribution of payments between short-term and long-term creditors proposed by different regimes in the event of a crisis to be immaterial. What matters instead is how they affect total expected payments to creditors in these events. The higher are these expected payments, the better is the country's market access ex ante as long as it is credible that it will "call" the IFI in the first place. This is an important restriction on restructured payments: they should not be so high as to violate the country's ex post incentive compatibility constraint.

Our framework contains an important assumption that enable restructuring regimes to harness these welfare gains: it assumes that debt restructurings halt all issues of new bonds. This feature prevents the country from borrowing excessively in the aftermath of a restructuring and thus diluting the restructured debt. Without this restriction, it is conceivable that both restructuring and reprofiling could in fact reduce 
expected payments to creditors in the event of a crisis, even if the actual terms at which debt is restructured are favorable to creditors. Thus, our analysis suggests that the ultimate welfare effects of restructuring regimes may depend on their ability to control the country's market access for some time after they are activated.

More generally, it could be argued that restructuring regimes may resolve some inefficiencies at the expense of aggravating others, by weakening the country's ex ante and ex post incentives to undertake certain desirable actions. To illustrate this possibility, consider a slight variation of our model in which expected payments to creditors depend not just on the structure of debt but also on other actions (e.g., structural reforms) taken by the country. For example, suppose that the country could, after borrowing in period 0 , decide the extent to which output is pledgeable to foreign creditors. In such a scenario, which is similar to Jeanne (2009), short-term debt would have additional value as a disciplining device. In particular, by holding short-term debt the country would leave itself open to costly roll-over crises in period 1 if the pledgeability of debt had not be altered satisfactorily. In this context, a restructuring regime that reduces the ex post cost of crises may raise their likelihood by weakening the country's incentives to implement reforms, potentially reducing welfare. ${ }^{25}$

Finally, different restructuring regimes also affect the IFI's incentives to intervene during debt crises. It is widely perceived, for instance, that an advantage of current debt restructurings relative to the proposed reprofiling alternative is that the former deals with debt problems "once and for all", whereas reprofilings may exacerbate debt overhang by postponing resolution. This possibility could be easily introduced into our model by assuming that, although reprofiling has a lower cost of default than reprofiling, it entails a loss of output due to debt overhang. This should not be a problem if the country and the IFI correctly internalize these costs since, presumably, the IFI would choose to apply the correct regime. One might imagine, however, situations in which the IFI's preferences are skewed towards creditors so that it minimizes creditor losses ex post, e.g. reprofiling debt even when a restructuring would be socially optimal. In such cases, the country might prefer not to approach the IFI altogether and, in this way, the option to reprofile debt may reduce welfare relative to regime in which an outright restructuring is the only available policy.

At a more general level, the insights offered by this paper should play an important role in the various debates regarding the reform of the international financial architecture. This paper has focused on the maturity structure of debt, since the reforms under consideration have different effects on short- versus long-term creditors. To examine the effects of other reforms under discussion, such as the strengthening of collective action clauses, it would be important to model other dimensions of the debt structure, such as the type and jurisdiction of instruments being issued. ${ }^{26}$ This constitutes an important avenue for future research.

\footnotetext{
${ }^{25}$ This is similar to the result of Hatchondo et al. (2014) who show in a quantitative model that an improvement in the ability to renegotiate debt may reduce ex ante welfare. The conjecture is that, by reducing the costs of default, such a modification of the environment aggravates the problem of debt dilution, thereby reducing welfare.

${ }^{26}$ See, for instance, IMF $(2014 \mathrm{a}, \mathrm{c})$.
} 


\begin{tabular}{ccc}
$t=0$ & $t=1$ & $t=2$ \\
\hline & $p$ realized & $\theta$ realized
\end{tabular}

country chooses

$b=\left(b_{01}, b_{02}\right)$

investment

$$
\text { country issues } b_{12}
$$

$$
\text { debt payments }
$$$$
\text { disinvestment } \delta
$$$$
\text { consumption }
$$

debt payments

consumption

Figure 1: Timeline 
Disinvest and default in period 1

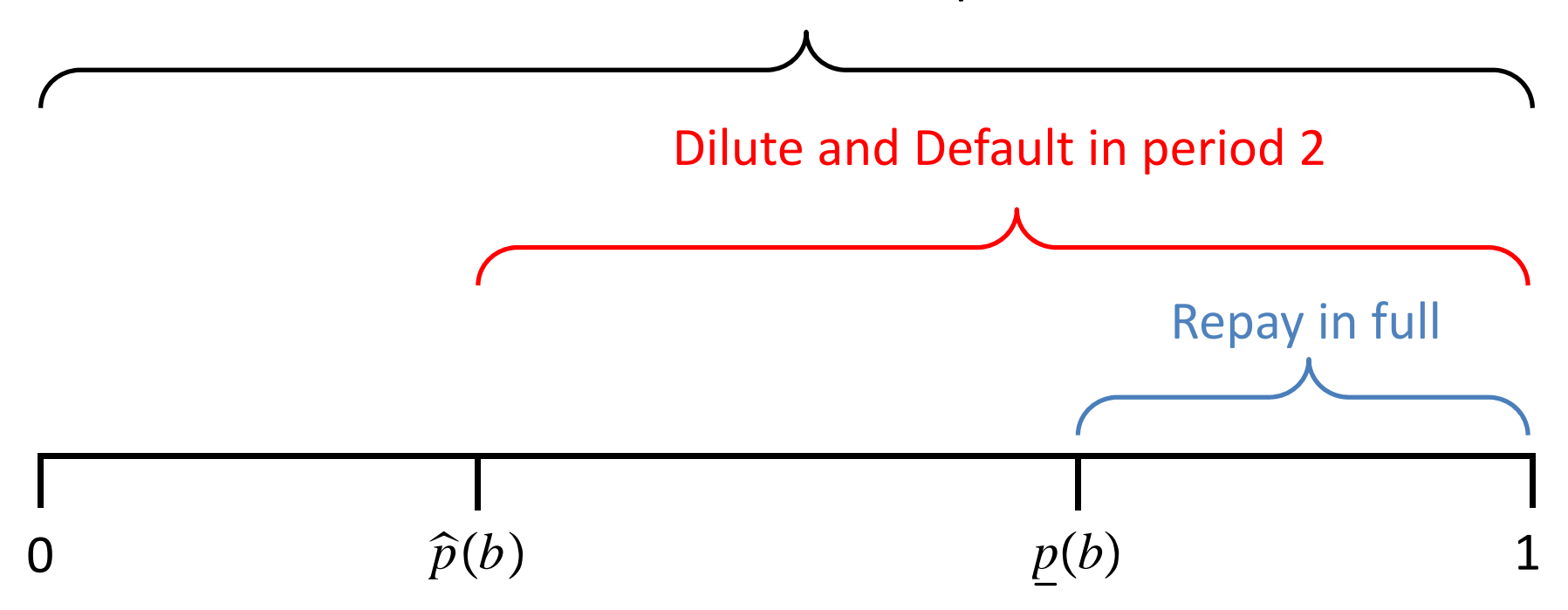

Figure 2: Feasible strategies in period 1 


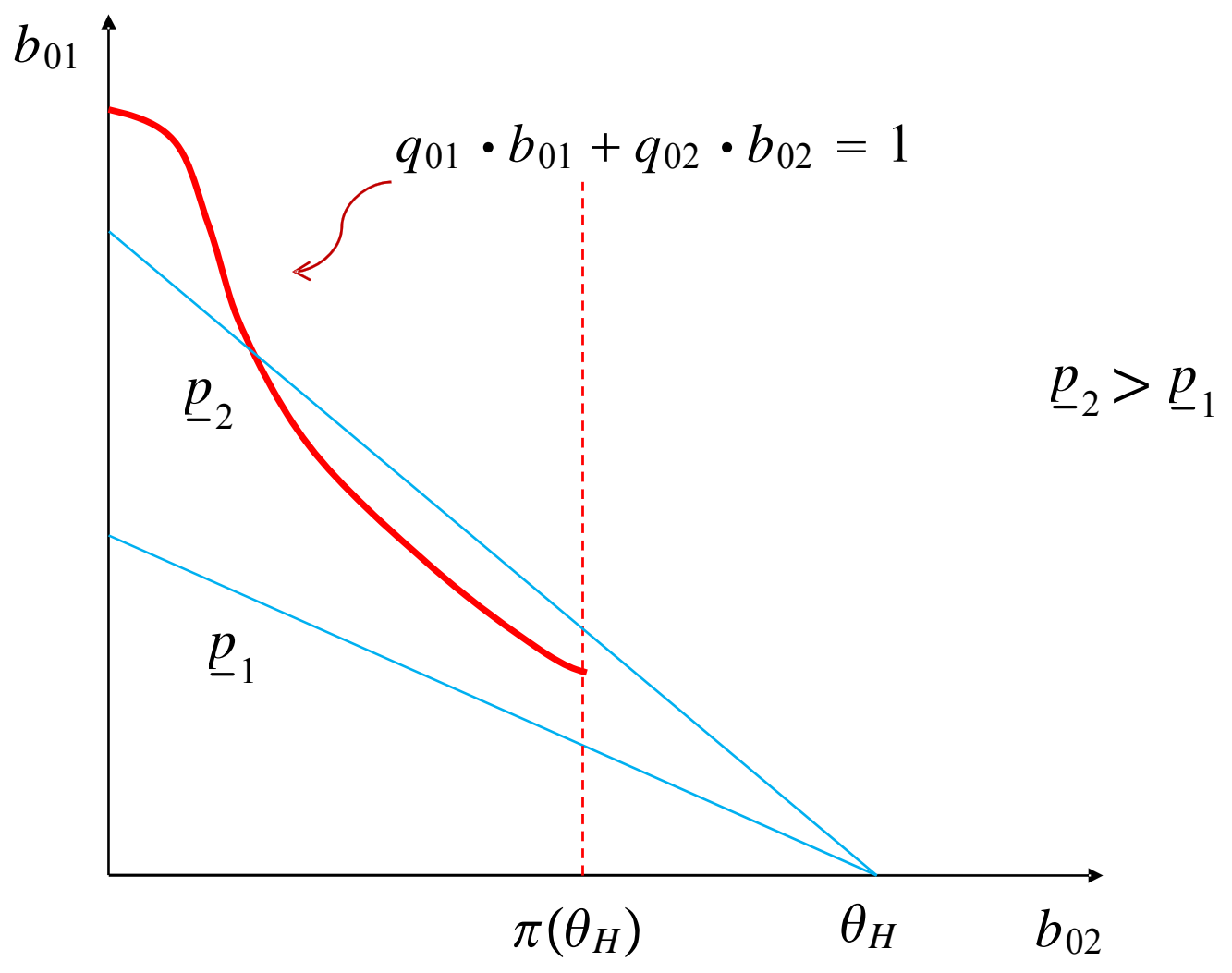

Figure 3 


\section{Panel I}

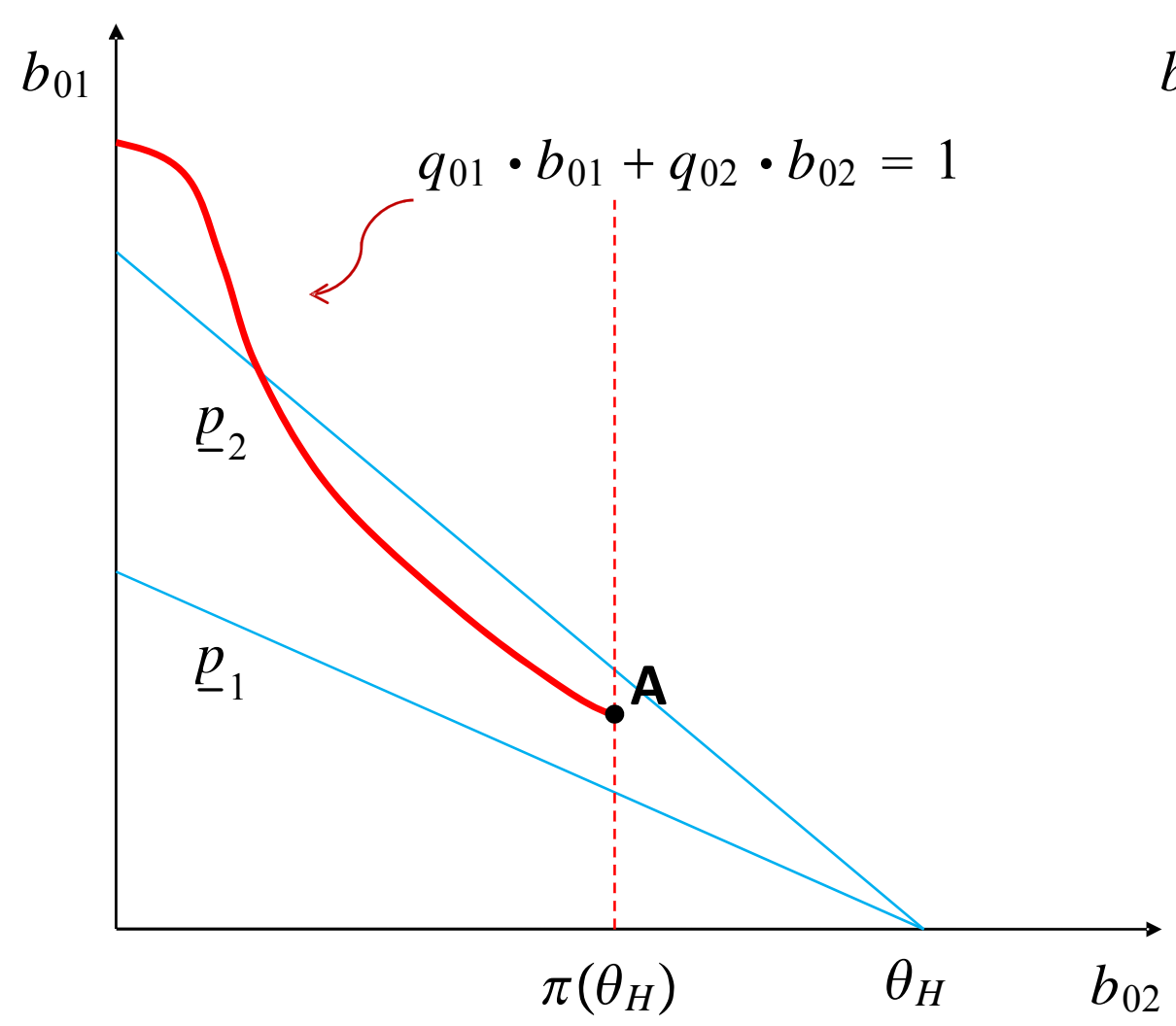

\section{Panel II}

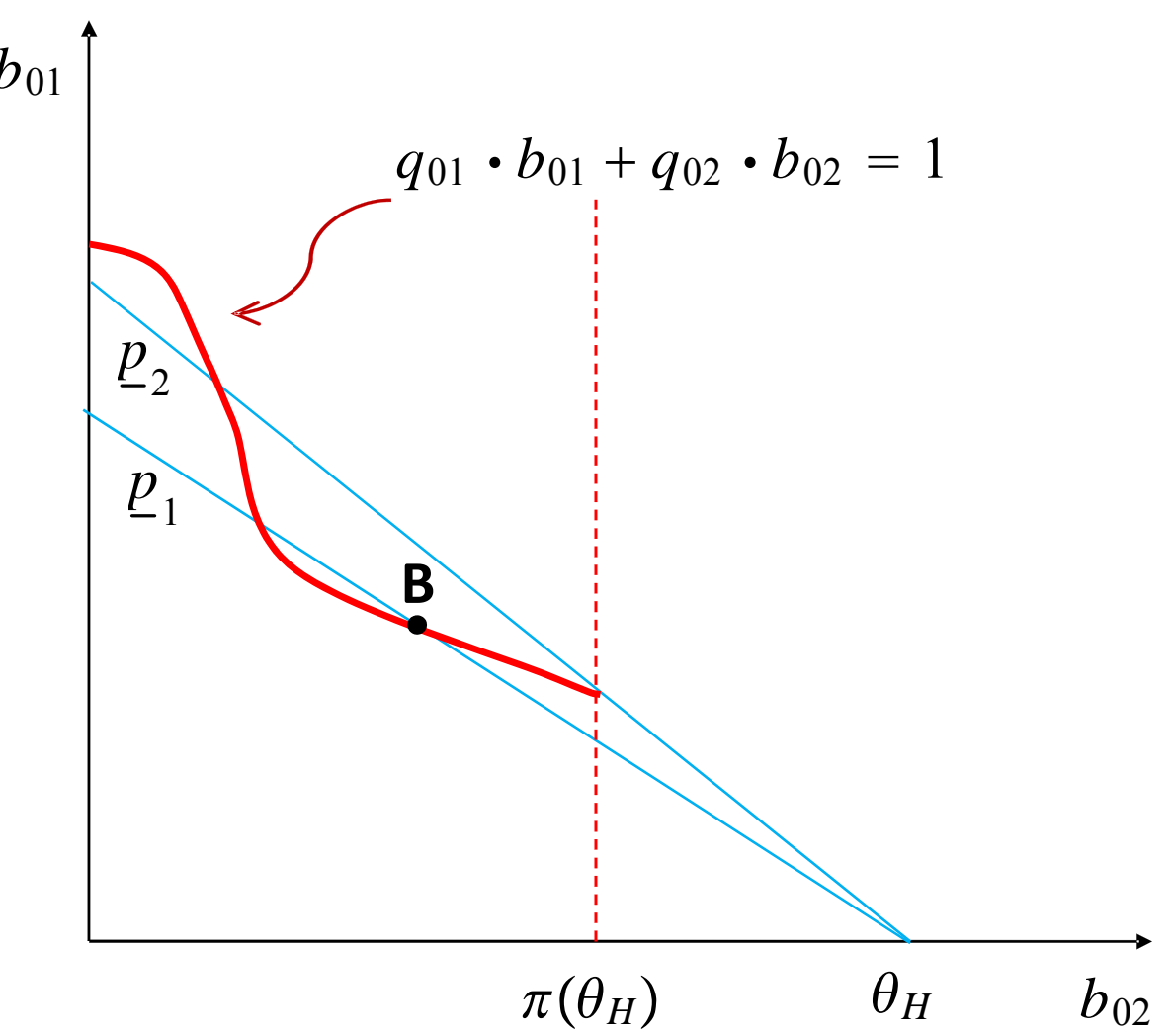

Figure 4 


\section{References}

[1] Aguiar, M. and M. Amador (2013), "Take the Short Route: How to Repay and Restructure Sovereign Debt with Multiple Maturities", mimeo, Princeton University.

[2] Aguiar, M. and M. Amador, (2014), "Sovereign Debt." Handbook of International Economics Vol 4. North-Holland: 647-87.

[3] Angeletos, G., (2002), "Fiscal Policy with Noncontingent Debt and the Optimal Maturity Structure," The Quarterly Journal of Economics, MIT Press, MIT Press, vol. 117(3), 1105-1131, August.

[4] Arellano, C. and A. Ramanarayanan, (2012), "Default and the Maturity Structure in Sovereign Bonds," Journal of Political Economy, University of Chicago Press, University of Chicago Press, vol. 120(2), 187 $-232$.

[5] Bai, J., T.S. Kim and G. Mihalache (2014), "The Maturity and Payment Structure of Sovereign Debt", mimeo, Rochester.

[6] Bolton, P. and O. Jeanne, (2007), "Structuring and Restructuring Sovereign Debt: The Role of a Bankruptcy Regime," Journal of Political Economy, vol. 115(6).

[7] Bolton, P. and O. Jeanne, (2009), "Structuring and Restructuring Sovereign Debt: The Role of Seniority," Review of Economic Studies, Oxford University Press, vol. 76(3), 879-902.

[8] Borensztein E. and U. Panizza, (2009), "The Costs of Sovereign Default," IMF Staff Papers, Palgrave Macmillan, vol. 56(4), 683-741, November.

[9] Broner, F., G. Lorenzoni and S. Schmukler, (2013), "Why Do Emerging Economies Borrow Short Term?," Journal of the European Economic Association, European Economic Association, vol. 11, 67$100,01$.

[10] Brunnermeier, M., and M. Oehmke, (2013), "The Maturity Rat Race," The Journal of Finance 68(2), 483-521.

[11] Buchheit, L, M. Gulati and I. Tirado, "Guest post: The case for sovereign reprofiling the IMF way, part one," Financial Times, 11/7/2014

[12] Brooke, M., R. Mendes, A. Pienkowski and E. Santor ( 2013), "Sovereign Default and State-Contingent Debt." Bank of Canada joint study with the Bank of England.

[13] Brooks, S. and D. Lombardi (2015), Sovereign Debt Restructuring, Cigi Papers, 65.

[14] Buera, F. and J. Nicolini, (2004), "Optimal maturity of government debt without state contingent bonds," Journal of Monetary Economics, Elsevier, vol. 51(3), 531-554, April. 
[15] Calvo, G., (1988), "Servicing the Public Debt: The Role of Expectations", American Economic Review, $78(4), 647-661$.

[16] Chatterjee, S. and B. Eyigungor, (2012), "Maturity, Indebtedness, and Default Risk," American Economic Review, American Economic Association, vol. 102(6), 2674-99, October.

[17] Cole, H. and T. Kehoe, (2000), "Self-Fulfilling Debt Crises," Review of Economic Studies, Wiley Blackwell, vol. 67(1), 91-116, January.

[18] Corsetti, G., B. Guimaraes and N. Roubini (2006), "International Lending of Last Resort and Moral Hazard: a Model of IMF's Catalytic Finance," Journal of Monetary Economics, 53(3), 441-471.

[19] Debortoli, D., R. Nunes and P. Yared, (2014), "Optimal Government Debt Maturity under Limited Commitment", mimeo UPF.

[20] Diamond, P. and R. Rajan (2001), "Liquidity Risk, Liquidity Creation and Financial Fragility: a Theory of Banking", Journal of Political Economy 109(2), 287-327.

[21] Fernandez, R. and A. Martin (2015), "The Long and the Short of It: Sovereign Debt Crises and Debt Maturity", NBER working paper.

[22] Hatchondo, J., L. Martinez and C. Sosa Padilla (2014), "Voluntary Sovereign Debt Exchanges" Journal of Monetary Economics.

[23] Hatchondo, J., L. Martinez and C. Sosa Padilla (2015), "Debt Dilution and Sovereign Default Risk," Journal of Political Economy.

[24] International Monetary Fund, (2014a), "Strengthening the Contractual Framework to Address Collective Action Problems", available at www.imf.org.

[25] International Monetary Fund, (2014b), "The Fund's Lending Framework and Sovereign Debt - Preliminary Considerations", available at www.imf.org.

[26] International Monetary Fund, (2014c), "IMF Supports Reforms for More Orderly Sovereign Debt Restructurings," IMF Survey Magazine: in the News, October 6.

[27] Jeanne, O., (2009), "Debt Maturity and the International Financial Architecture," American Economic Review, American Economic Association, vol. 99(5), 2135-48, December.

[28] Lorenzoni, G. and I. Werning, (2014) "Slow Moving Debt Crises," mimeo, MIT.

[29] Sandleris, G., (2012), "The Costs of Sovereign Defaults: Theory and Empirical Evidence," mimeo DiTella.

[30] Yue, Vivian Z., (2010) "Sovereign Default and Debt Renegotiation," Journal of International Economics 80:2, 176-187. 


\subsection{Optimal debt structure}

Proposition 1 The optimal debt structure $b^{*}$ may entail $b_{02}^{*}<\pi\left(\theta_{H}\right)$.

Proof. Assume that the country begins at an arbitrary debt structure $b$. Suppose that it reduces $b_{01}$ and increases $b_{02}$ so as to keep $\underline{p}(b)$ constant. This reduces $\widehat{p}(b)$, which depends only on $b_{01}$. Thus, unless the change in debt structure reduces revenues, the original debt structure could not have been optimal: otherwise, it would be possible for the country to finance the project with lower values of both, $\underline{p}(b)$ and $\widehat{p}(b)$. We show, however, that the impact of any such change on revenues is on general ambiguous.

By differentiating the expression for $\underline{p}(b)$ in equation (8), it follows that the country can substitute ST and LT bonds at rate

$$
\left.\frac{d b_{01}}{d b_{02}}\right|_{\underline{p}}=-\frac{p}{R}
$$

and keep $\underline{p}(b)$ constant.

We can also express the revenues obtained by a particular debt structure that satisfies the IC constraint as

$$
q_{01}(b) \cdot b_{01}+q_{02}(b) \cdot b_{02}=\int_{0}^{\widehat{p}(b)} \frac{F(1, p)}{R} \cdot d G(p)+\int_{\widehat{p}(b)}^{1} \frac{b_{01}}{R} d G(p)+\int_{\underline{p}(b)}^{1} p \cdot \frac{b_{02}}{R^{2}}
$$

Differentiating this expression with respect to $b_{01}$ subject to keeping $\underline{p}$ constant (equation (23)), we can write

$$
\frac{d \widehat{p}(b)}{d b_{01}} \cdot\left(\frac{F(1, \widehat{p})}{R}-\frac{b_{01}}{R}\right) \cdot d G(\widehat{p}(b))+\left[\int_{\widehat{p}(b)}^{1} \frac{1}{R} d G(p)-\int_{\underline{p}(b)}^{1} \frac{\underline{p}}{\underline{p}} \cdot \frac{1}{R} d G(p)\right]
$$

The first term in the expression captures the fall in revenue that results from the increase in $\widehat{p}(b)-$ and thus from the greater instances of disinvestment - associated with a rise in $b_{01}$. The term in square brackets captures instead the change in revenue that results from changing the composition of $b$ so as to keep $\underline{p}$ constant, for a given $\widehat{p}$. That is, it reflects the change in revenue arising, above $\widehat{p}$, from greater payments to ST creditors vs. lower payments to LT creditors above $\widehat{p}$.

In general, the sign of the term in square brackets is ambiguous, though it can be signed when there is only ST debt. In that case, $\widehat{p}=\underline{p}$ and thus the term is negative, so that revenue necessarily increases when $b_{01}$ falls and $b_{02}$ increases. This implies that it is never optimal for the country to issue only ST debt, since it can - by lengthening its maturity structure - increase revenues while reducing $\widehat{p}(b)$ and keeping $\underline{p}(b)$ constant. In all other cases, the term in brackets may be positive or negative depending on $\widehat{p}(b), \underline{p}(b)$ and on the distribution function $G(\cdot)$. This means that, in general, it is impossible to rule out the possibility that the optimal debt structure $b^{*}$ entails $b_{02}^{*}<\pi\left(\theta_{H}\right)$. 